\title{
Long term seismic response monitoring and finite element modeling of a concrete building considering soil flexibility and non-structural components
}

\author{
Faheem Butt, Piotr Omenzetter* \\ Dept. of Civil \& Environmental Engineering, The University of Auckland, Private Bag 92019, \\ Auckland 1142, New Zealand
}

\begin{abstract}
This paper presents a study of the variation of natural frequencies and damping ratios of a reinforced concrete building identified from earthquake records during a period of four years. The three storey reinforced concrete building is instrumented with five tri-axial accelerometers. The state-space subspace system identification technique was used to ascertain the natural frequencies and damping ratios considering 50 recorded earthquake response time histories. Correlations were developed between the peak ground acceleration at the base level and peak response acceleration at roof level with identified frequencies and damping ratios. It was found that modal characteristics of the building are sensitive to the level of excitation and response. A general trend of decreasing fundamental frequencies and increasing damping ratios with increased level of shaking was observed. A three dimensional finite element model of the building was developed to study the influences of soil and various structural and non-structural components. To incorporate real in-situ conditions, soil underneath the foundation was modeled using spring elements and non-structural components (cladding, in-fills and partitions) were also included. It was concluded from the investigation that participation of soil and non-structural components towards the seismic response of the building is significant and these should be considered in models to simulate the real behavior.
\end{abstract}

Keywords: Structural health monitoring, system identification, seismic response, finite element modeling, soil-structure interaction, non-structural components

\section{INTRODUCTION}

The characterization and prediction of the response of civil structures under extreme loading events such as earthquakes is a challenging problem and has gained increasing attention in recent years. The challenges associated with the civil structures such as buildings, bridges and dams include modeling their complicated interaction with the surrounding ground, varying environmental and loading conditions, and complex material and structural behavior which preclude the study of a complete system in a laboratory setting. An approach to tackle these issues is to use the recorded responses from instrumented structures and extract the dynamic characteristics using a process known as system identification ${ }^{1,2}$. The in-situ measured responses reflect all the real physical properties of the structure and can be useful for structural health monitoring and model updating studies ${ }^{3,4}$.

In characterizing the dynamic response of buildings, natural frequencies and damping ratios are very important parameters. Permanent instrumentation of buildings makes possible studying of these parameters under different earthquakes excitation. Studies have shown that the dynamic characteristics tend to vary with vibration amplitude ${ }^{5,6,7}$. It is, therefore, important to examine the behavior of buildings under different excitation scenarios. The trends of variation of dynamic characteristics like modal frequencies and damping ratios thus developed will provide quantitative data for the variations in the behavior of buildings. Moreover, such studies will provide invaluable information for the development and calibration of realistic models for the prediction of seismic response of structures in model updating and structural health monitoring studies.

*p.omenzetter@auckland.ac.nz; phone 649373 7599-88138; www.auckland.ac.nz

For predicting the response of structures, finite element modeling is required to produce models which can replicate true characteristics of the structures. An important factor in the modeling of civil engineering structures is the effect of soil- 
structure-interaction (SSI). SSI involves transfer of energy from the ground to the structure and back to the ground ${ }^{8}$. Due to the flexibility of soil, the natural period can be longer than the period of the fixed base building. Building period has important effects on the design and analysis of earthquake resistant structures. Proper modeling of soil-structure interaction is, therefore, necessary to better predict the actual response of structures. Another important aspect of structural modeling is the consideration of non-structural components (NSCs). It is a common practice to ignore NSCs like partition walls and claddings in a FEM. However, studies, e.g., Su et al. ${ }^{9}$ have demonstrated that while the effect of a single NSC on dynamic response of a building can be negligible their cumulative effect can be significant. The numerical results achieved by modeling of the NSCs reveal the participation of these components during shaking of the structures. The level of participation depends upon the extent of shaking. Usually the plasterboard clad walls are considered to be providing no significant contribution towards lateral stiffness. However, it was shown by physical testing by Liew et al. ${ }^{10}$ that these types of walls provide lateral stiffness and strength during seismic events. It is therefore necessary to incorporate the effect of NSCs adequately into FEM.

This study comprises two parts. In the first part, the variation in dynamic response of the instrumented building using 50 recorded earthquakes will be evaluated. State-space subspace system identification technique will be used to estimate the frequencies and damping ratios. For natural input modal analysis, this technique is considered to be the most powerful class of the known system identification techniques in the time domain ${ }^{11}$. Relations between peak ground acceleration (PGA) at the base level of the building and peak response acceleration (PRA) at the roof level are developed with the estimated frequencies and damping ratios. The variation in frequencies and damping ratios in each mode is evaluated. The second part is a study of the building dynamics by incorporating the soil flexibility and NSCs. To ascertain the influence of structural and non-structural components, FEMs were constructed considering different cases, i.e., bare fixed base frame, frame with slabs, lift shaft, NSCs, soil under foundation and the building partly submerged in soil, respectively. The FEM and the largest recorded earthquake response are then compared. The study attempts to highlight the importance of modeling the soil and NSCs to simulate the real behavior of the structures and is expected to further the understanding of the seismic response of buildings by providing quantitative data for structural health monitoring and model updating studies.

\section{DESCRIPTION OF THE BUILDING, INSTRUMENTATION AND STRONG MOTION DATA}

\subsection{Building description}

The building under study is situated at Lower Hutt approximately 20km north-east of Wellington, New Zealand. It is a three storey reinforced concrete (RC) structure with a basement. The structural system consists of beam-column frames and a $229 \mathrm{~mm}$ thick reinforced concrete shear core, which houses an elevator. The plan of the building is rectangular but the beams along the longitudinal direction inside the perimeter beams and shear core make it unsymmetrical in terms of stiffness distribution (Figure 1). All the exterior beams are $762 \times 356 \mathrm{~mm}$ except at the roof level where these are $1067 \times 356 \mathrm{~mm}$. All the interior beams and columns are rectangular $610 \times 610 \mathrm{~mm}$. Floors are $127 \mathrm{~mm}$ thick reinforced concrete slabs except a small portion of ground floor near the stairs where it is $203 \mathrm{~mm}$ thick. The roof comprises corrugated steel sheets over timber planks supported by steel trusses. The building is resting on separate pad type footings of base dimensions $2.29 \times 2.29 \mathrm{~m}$ at the perimeter and $2.74 \times 2.74 \mathrm{~m}$ inside the perimeter and $610 \times 356 \mathrm{~mm}$ tie beams are provided to join all the footings together.

\subsection{Sensor array}

The building is instrumented, as part of the GeoNet project, with five tri-axial accelerometers. Two accelerometers are fixed at the base level, two at the roof level and one underneath the first floor slab as shown in Figure 2. The sensor array was configured to trigger on an event between 2007 and 2009 but since then it has been recording continuously and had recorded many earthquakes since its installation in early November 2007. All the data is stored to a central recording unit and is available online (www.geonet.org.nz).

\subsection{Earthquake selection criteria}

For this study, 50 earthquakes recorded during a period from November 2007 till February 2010 on the building with epicenters within $200 \mathrm{~km}$ from the building were selected. The reason for adopting this was to select earthquakes of such intensities which can be recorded on the sensors and can shake the modes of interest quite well. The area surrounding the building had not been hit by any strong earthquake since its instrumentation. Almost all of the 50 recorded earthquakes 
have Richter magnitude ranging from 3 to 5 except a very few that have more than 5 , with 5.2 being the maximum recorded. This means that nearly all of the earthquakes fall into the category of low intensity except a very few that can be treated as moderate events. Examples of the time histories of one of the recorded earthquakes are shown in the Figures $3 \mathrm{a}, \mathrm{b}$ and $4 \mathrm{a}, \mathrm{b}$.

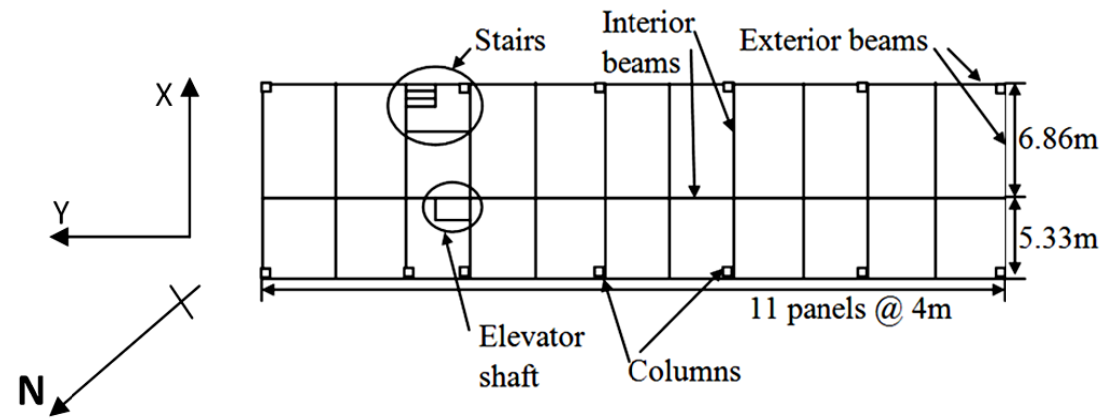

Figure 1. A typical floor plan showing the location of stairs and elevator shaft.
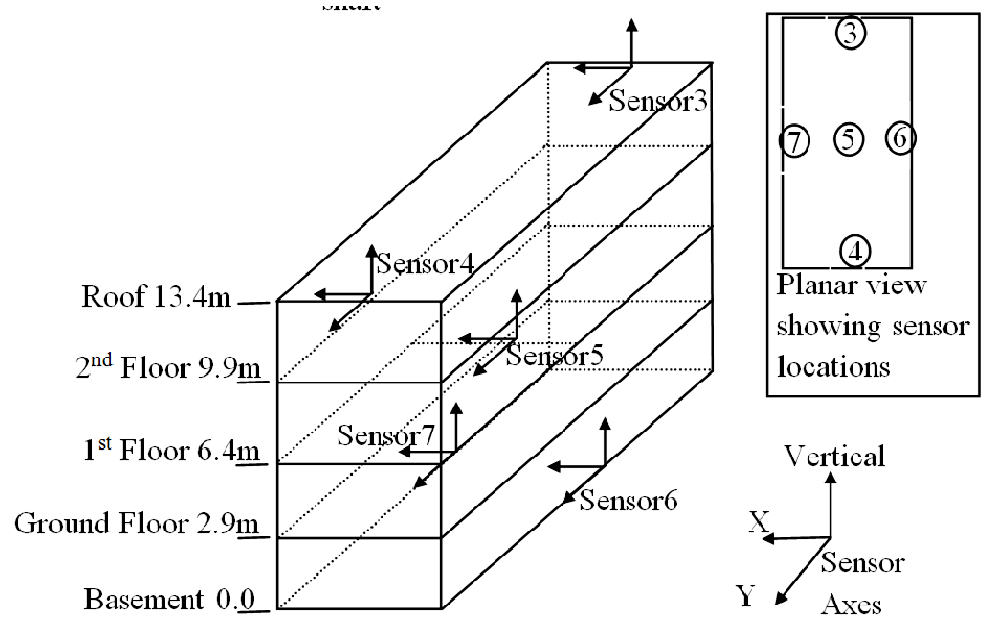

Figure 2. Building sensor array.

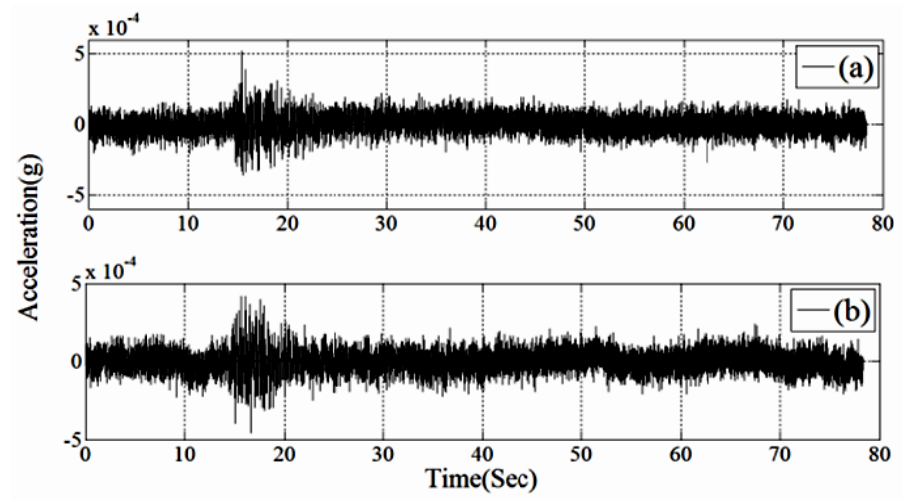

Figure 3. Building base seismic acceleration time histories from sensor 6: (a) X-component (b) Y-component. 


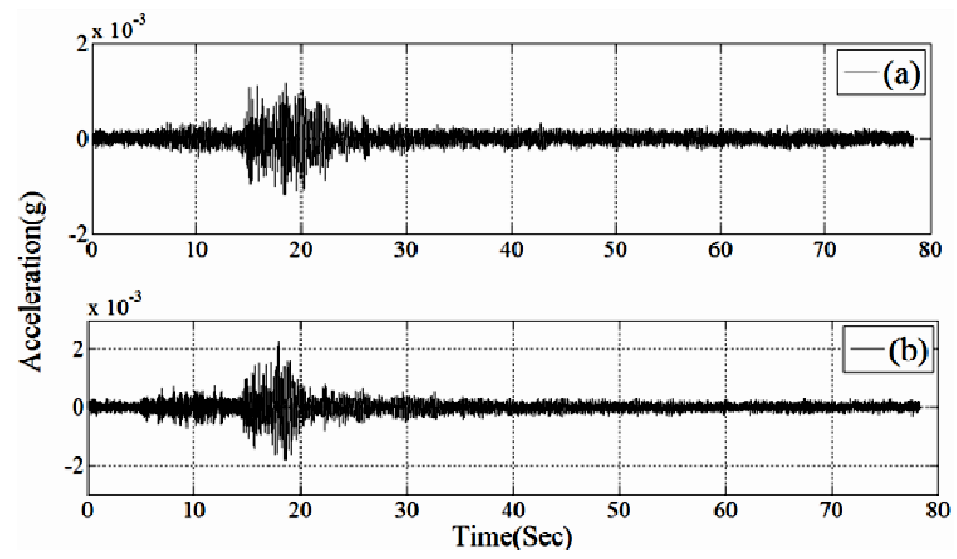

Figure 4. Building roof seismic acceleration time histories from sensor 4: (a) X-component (PRA) (b) Y-component.

\section{EVALUATION OF VARIATION OF SEISMIC RESPONSE OF THE BUILDING}

The objective of this part of the research is to study the relationship between PGA, PRA and the identified first three natural frequencies and corresponding damping ratios of the building for the considered 50 earthquakes. For identification of frequencies and damping ratios state-space subspace system identification technique was used.

\subsection{State-space subspace system identification technique}

After sampling of a continuous time state space model, the discrete time state space model can be written as:

where $\boldsymbol{A}, \boldsymbol{B}, \boldsymbol{C}$ and $\boldsymbol{D}$ are the discrete state, input, output and control matrices respectively, whereas $\boldsymbol{u}_{k}$ is the excitation vector and $\boldsymbol{x}_{k}, \boldsymbol{y}_{k}$ are the discrete time state and output vectors, respectively. In reality, there are always process and measurement noises present so adding these to the above equations result in:

Here $\boldsymbol{w}_{k}$ and $\boldsymbol{v}_{k}$ are the process and measurement noise, respectively. The data from output $\boldsymbol{y}_{\boldsymbol{k}}$ and/or input $\boldsymbol{x}_{\boldsymbol{k}}$ is assembled in a block Hankel matrix, which is defined as a gathering of a family of matrices that are created by shifting the data matrices in time. After this, the identification involves two steps. The first step takes projections of certain subspaces calculated from input and output observations (in block Hankel matrix) to estimate the state sequence of the system. This is usually achieved using singular value decomposition (SVD) and QR decomposition. In the second step, a least square problem is solved to estimate the system matrices $\boldsymbol{A}, \boldsymbol{B}, \boldsymbol{C}$ and $\boldsymbol{D}$. Then the modal parameters, i.e. frequencies, damping ratios and mode shapes, are found by eigenvalue decomposition of the system matrix $\boldsymbol{A}$. Further details of the identification process can be found elsewhere ${ }^{12}$.

\subsection{Application of state-space subspace system identification technique to the instrumented building}

The state-space subspace identification technique derives state-space models for linear systems by applying the wellconditioned operations, like SVD, to the block Hankel data matrices. In order to determine the proper system order, the trend of the estimated modal parameters in a stabilization chart is observed. Stability tolerances are chosen based on the relative change in the modal properties of a given mode as the system order increases. In this research, an identified frequency was considered to be stable if the absolute deviation between the frequency identified at the present and previous order was less than or equal to $0.01 \mathrm{~Hz}$. A stable damping ratio was defined by a deviation less than $5 \%$. For mode shapes stability, model assurance criterion (MAC) between the mode shapes of the present and previous orders 
was to be at least $95 \%$ or greater. MAC is an index that determines the similarity between two mode shapes. For modes $\phi_{1}$ and $\phi_{j}$ the MAC is defined as ${ }^{13}$ :

$$
M A C=\frac{\left(\boldsymbol{\phi}_{i}^{T} \boldsymbol{\phi}_{j}\right)^{2}}{\left(\boldsymbol{\phi}_{i}^{T} \boldsymbol{\phi}_{i}\right)\left(\boldsymbol{\phi}_{j}^{T} \boldsymbol{\phi}_{j}\right)}
$$

In the above equation superscript $T$ denotes matrix transpose. In the Figure 5, the marker sign "black dot" shows all the identified frequencies, the "red dot" shows the stable frequencies with damping ratios, while "red dot with blue circle" the stable frequencies with damping ratios and mode shapes. Sampling rate of the digitized signals was $200 \mathrm{~Hz}$ and for establishing the stabilization diagrams system orders from 0 to 160 were evaluated. For system identification, sensors 6 and 7 were taken as the inputs (excitations) while sensors 3, 4 and 5 as the outputs (responses).

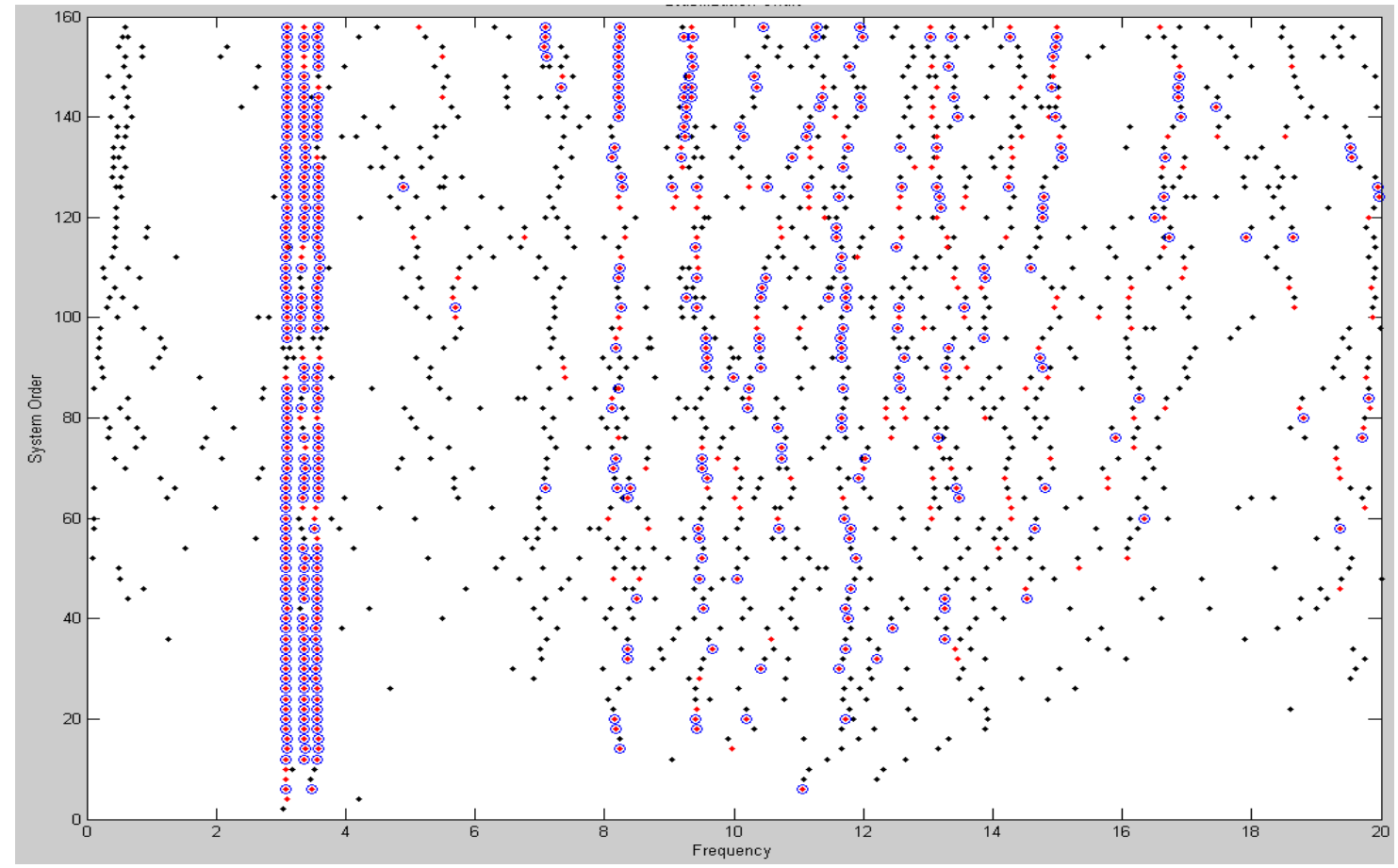

Figure 5. A typical stabilization diagram showing stable identified modes. Marker sign "black dot" shows all identified frequencies, "red dot" stable frequency and damping ratio, and "red dot with blue circle" stable frequency, damping ratio and mode shape.

The typical first three mode shapes of the building are shown in Figure 6 in planar view. The shape of the first mode shows it to be a translational mode along X-direction with a little rotation. The second mode is nearly purely torsional and the third one is a dominant translational mode along Y-direction coupled with some torsion. Structural irregularity, due to the internal longitudinal beams being not in the middle of the transverse direction of the building and shear core present near the North end, creates unsymmetrical distribution particularly of stiffness which has caused the modes to be coupled translational-torsional. Another important source of irregularities is likely non-uniformity of the soil underneath the foundations and surrounding the building.

\subsection{Correlation of PGA and PRA}

In this study, PRA of sensor 4 (at the roof) and PGA of sensor 6 (at the base) were considered. The maximum recorded PRA of the building is $0.041 \mathrm{~g}$ in the Y-direction and is double of that in the X-direction $(0.021 \mathrm{~g})$ (Figures $7 \mathrm{a}$ and $\mathrm{b}$ ). However, there is only one point in that maximum range and all the other points are below $0.015 \mathrm{~g}$. The $R^{2}$ coefficient shown in the plots is used to calculate the fit of a regression line. The closer this value is to 1.0, the better the fit. It can 
be seen that PGA and PRA have good correlations along both X and Y-directions, $R^{2}=0.84$ and $R^{2}=0.86$, respectively. Therefore, frequencies and damping ratios relations are plotted with one of them only, namely PRA.

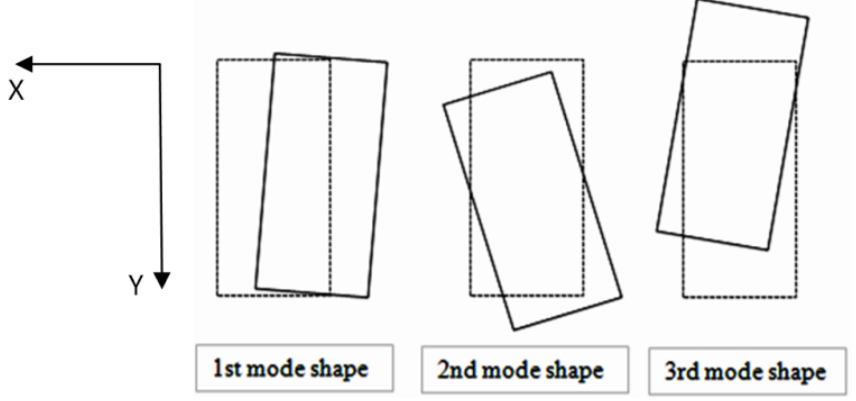

Figure 6. Planar view of typical first three mode shapes of the building
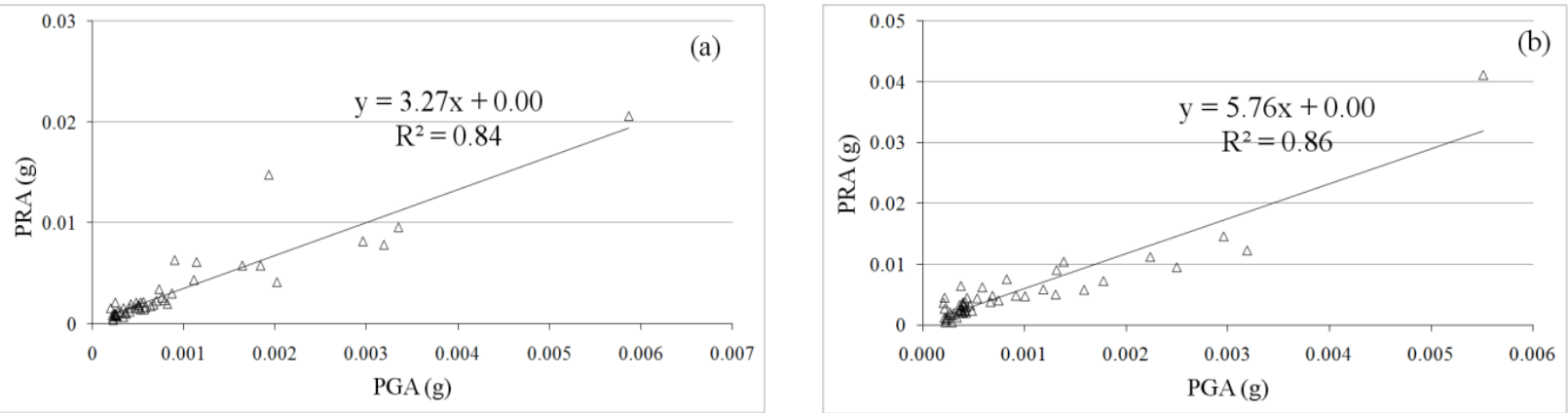

Figure 7. PRA vs. PGA of the building for 50 earthquake records: (a) X-direction components, and (b) Y-direction components

\subsection{Frequency variation}

Table 1 shows the minimum, maximum, average and percentage change (= (maximum-minimum)/average $\times 100 \%)$ values of the identified frequencies and damping ratios for the selected 50 earthquakes. The percentage change for the selected 50 events for the building in the first, second and third modal frequencies are $13 \%, 14 \%$ and $10 \%$, respectively.

Frequencies are decreasing as the vibration amplitude is increasing and this is observed in all three modes along both $\mathrm{X}$ and $\mathrm{Y}$-directions (Figures 8a and $\mathrm{b})$. The first modal frequency has good correlation $\left(R^{2}=0.80\right)$ with PRA along Xdirection as compared to other two frequencies but the correlations with PRA of the three modal frequencies in the Ydirection are not as good as those in X-direction. There are only two and one points, respectively, in X and Y-directions plots of PRA vs. frequency beyond $0.015 \mathrm{~g}$ up to $0.042 \mathrm{~g}$. The understanding of correlations could be improved if there were more points in this range. Since most of the earthquakes are of low intensity, the region from 0 to $0.01 \mathrm{~g}$ is densely populated but beyond that there are very few points.

During some events, the first, second or third mode or any two of them were missing in the system identification results, which shows that during those particular events these modes did not vibrate strongly enough. It reflects the fact that response of the building is also sensitive to the frequency content of the earthquake. In some events, the second and third modal frequencies tended to be very close and the minimum difference between these two was found to be $0.03 \mathrm{~Hz}$. This shows the capability of state-space subspace identification technique to identify very closely spaced modes.

\subsection{Damping ratio variation}

The average values of damping ratio for the selected 50 events for the first, second and third modes are $2.7 \%, 4.7 \%$ and $2.8 \%$ respectively (Table 1 ). The identified damping ratios show considerable scatter. Along $\mathrm{X}$ and $\mathrm{Y}$-directions, the first mode damping ratio shows increasing trends with the increased level of shaking and their $R^{2}$ values reflect a better correlation than for the second and third mode damping ratios (Figures 9a-c and 10a-c). However, the second mode 
damping ratios, which correspond to a nearly purely torsional mode, do not show any clear trend (Figures 9b and 10b). The third mode is also showing signs of increasing damping with increased level of shaking with the exception of a few outliers (Figures 9c and 10c).

Table 1. Summary of identified frequencies and corresponding damping ratios for the 50 earthquakes

\begin{tabular}{|c|c|c|c|c|c|c|c|c|}
\hline \multirow{2}{*}{ Mode } & \multicolumn{4}{|c|}{ Frequency $(\mathrm{Hz})$} & \multicolumn{4}{|c|}{ Damping ratios (\%) } \\
\hline & Min. & Max. & Avg. & $\%$ change & Min. & Max. & Avg. & $\%$ change \\
\hline $1^{\text {st }}(\mathrm{X}$-translation $)$ & 3.07 & 3.51 & 3.37 & $13 \%$ & 0.4 & 4.5 & 2.7 & $150 \%$ \\
\hline $2^{\text {nd }}$ (torsion) & 3.33 & 3.85 & 3.67 & $14 \%$ & 1.4 & 7.0 & 4.7 & $119 \%$ \\
\hline $3^{\text {rd }}$ (Y-translation) & 3.55 & 3.92 & 3.80 & $10 \%$ & 1.2 & 7.9 & 2.8 & $235 \%$ \\
\hline
\end{tabular}

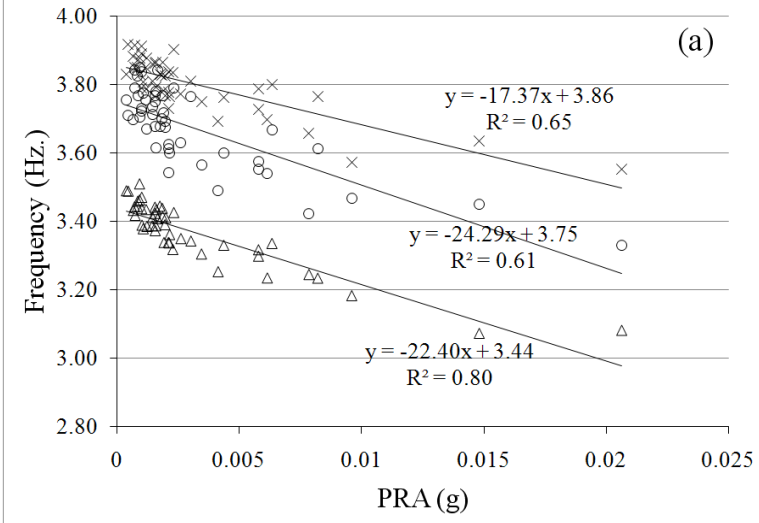

$\triangle 1$ st freq. vs EW-PRA $\circ 2$ nd Freq. vs EW-PRA $\times 3$ rd Freq. vs EW-PRA

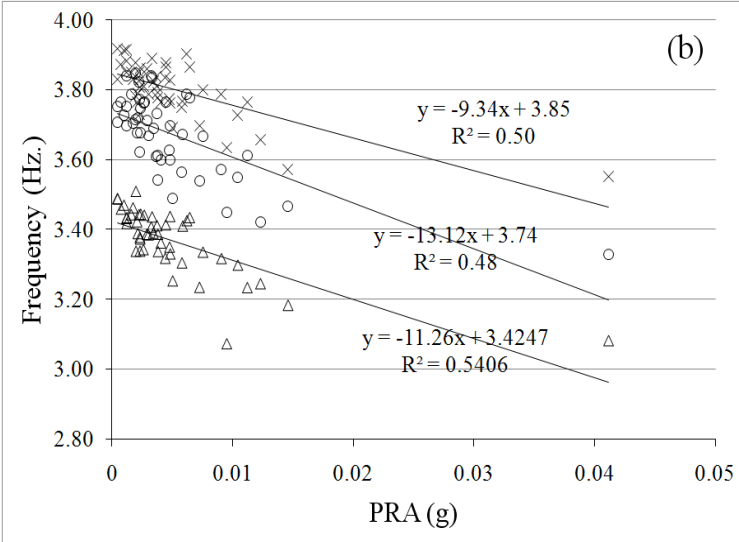

$\Delta$ st Freq. vs NS-PRA $\circ 2$ nd Freq. vs NS-PRA $\times 3$ rd Freq. vs NS-PRA

Figure 8. Identified first, second and third modal frequencies for 50 earthquakes vs. PRA: (a) X-direction components, and (b) Y-direction components
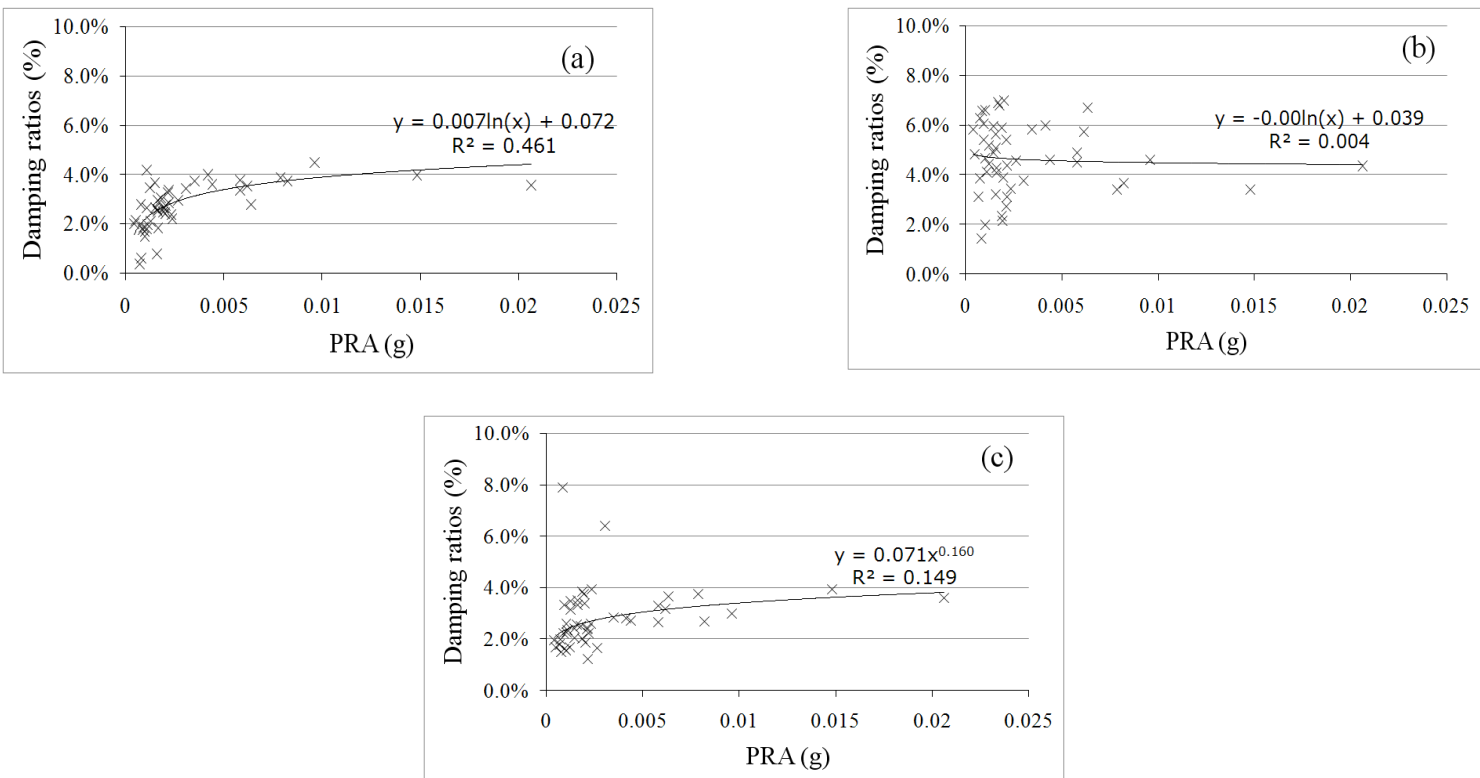

Figure 9. Identified damping ratios for 50 earthquakes: (a) first mode, (b) second mode and (c) third mode vs. X-direction PRA 

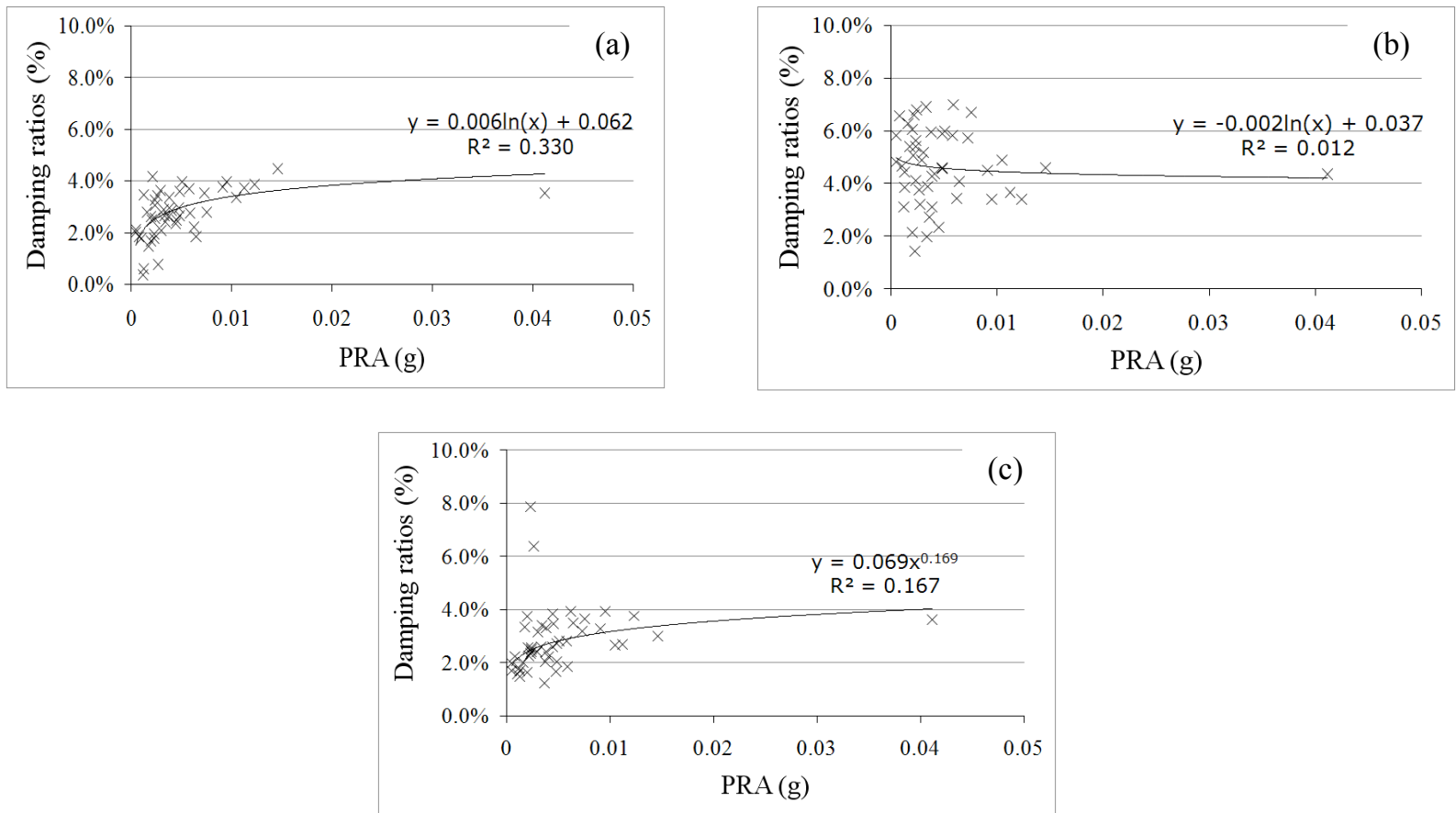

Figure 10. Identified damping ratios for 50 earthquakes: (a) first mode, (b) second mode and (c) third mode vs. Y-direction PRA

\section{FINITE ELEMENT MODELING OF THE INSTRUMENTED BUILDING}

To simulate the dynamic behavior of the building considering the soil flexibility and NSCs, a three dimensional FEM was developed using provided structural drawings and additional at-site measurements. The beams and columns were modeled as two node line elements, and floor slabs, stairs and shear core as four node shell elements. Linear elastic material properties were considered for the analysis. Initially the base was assumed as fixed and beam to column connections were also assumed as fixed (moment resisting frame assumption). The density and modulus of elasticity of concrete for all the elements was taken as $2400 \mathrm{~kg} / \mathrm{m}^{3}$ and $25 \mathrm{GPa}$ except for the shear core for which it was $2550 \mathrm{~kg} / \mathrm{m}^{3}$ and $26.5 \mathrm{GPa}$, respectively. The steel density and modulus of elasticity for roof elements were taken as $7800 \mathrm{~kg} / \mathrm{m}^{3}$ and 200GPa, respectively. The trusses present at the roof level were modeled as equivalent steel beams. The masses of the timber purlins, planks and steel corrugated sheet were calculated and lumped at the beams. All the dead and superimposed loads were applied as area loads or line loads at their respective positions. Figure 11 shows the three dimensional FEM having structural elements and NSCs (cladding, partition walls) and soil flexibility modeled in it.

Initially, the bare frame model with fixed base was developed which includes only the beams and columns. Then a series of FEMs were developed to ascertain the influence of the different structural elements, NSCs and soil, namely:

(a) bare fixed base frame;

(b) frame with slabs;

(c) frame with slabs and lift shaft;

(d) frame with slabs, lift shaft and NSCs modeled;

(e) frame with slabs, lift shaft, NSCs and soil underneath foundation modeled; and

(f) frame as in (e) with modeling of the building partly submerged in soil. 


\subsection{Idealization of soil}

Soil present at the site was classified according to the New Zealand Standard NZS1170 ${ }^{14}$ as class D (deep or soft soil). No other information was available regarding the soil properties. It was assumed that it is clay and corresponding properties for shear modulus, Poisson's ratio, density and shear wave velocity were taken from literature ${ }^{15}$.

In the FEM, soil was idealized using spring and dashpot elements. The values of static stiffness and radiation dashpot coefficients were calculated using the equations provided in Gazetas ${ }^{16}$. The dynamic stiffness coefficients were calculated by looking up the values of $a_{0}\left(=\omega B / V_{s}\right)$ and L/B from the charts provided in the above reference. Here $\omega$ is the circular frequency equal to $2 \pi f$ and this was taken as one of the earthquake dominant frequencies in the case of seismic excitation, whereas $B, L$ and $V_{s}$ are the half width, half length of the base of footing and the shear wave velocity respectively. The total stiffness was calculated by multiplying the static stiffness by dynamic stiffness coefficients. Material dashpot constant $2 \mathrm{~K} \beta / \omega$ was added to the radiation damping coefficient to estimate the total damping coefficient. Here $\mathrm{K}$ is the total stiffness calculated above and $\beta$ is the soil or material damping ratio which was taken as 0.05. A range for $\beta$ between 0 and 0.10 is suggested by Whitman and Richar ${ }^{17}$. Since the building is partially submerged in soil, equivalent horizontal soil springs were calculated using the submerged column as a footing and were included in the FEM.

\subsection{Idealization of NSCs}

External cladding in the building is made up of fiberglass panels with insulating material on the inner side. The density and modulus of elasticity values of fiberglass were taken from literature ${ }^{18}$ as $1750 \mathrm{~kg} / \mathrm{m}^{3}$ and $19 \mathrm{GPa}$, respectively. Claddings were modeled as four node thin shell elements. Since the structure under study is an office building, there are a large number of partition walls present. The stiffness values of gypsum wall partitions were taken from Kanvinde and Deierlein ${ }^{19}$ as $2800 \mathrm{kN} / \mathrm{m}$. The mass of the partition walls were calculated manually and applied as an area mass of $20 \mathrm{~kg} / \mathrm{m}^{2}$. Gypsum partition walls were modeled as two nodes link elements which are diagonal elements representing only stiffness along the longitudinal direction. The mass of false ceiling was taken as area mass of $12 \mathrm{~kg} / \mathrm{m}^{2}$.

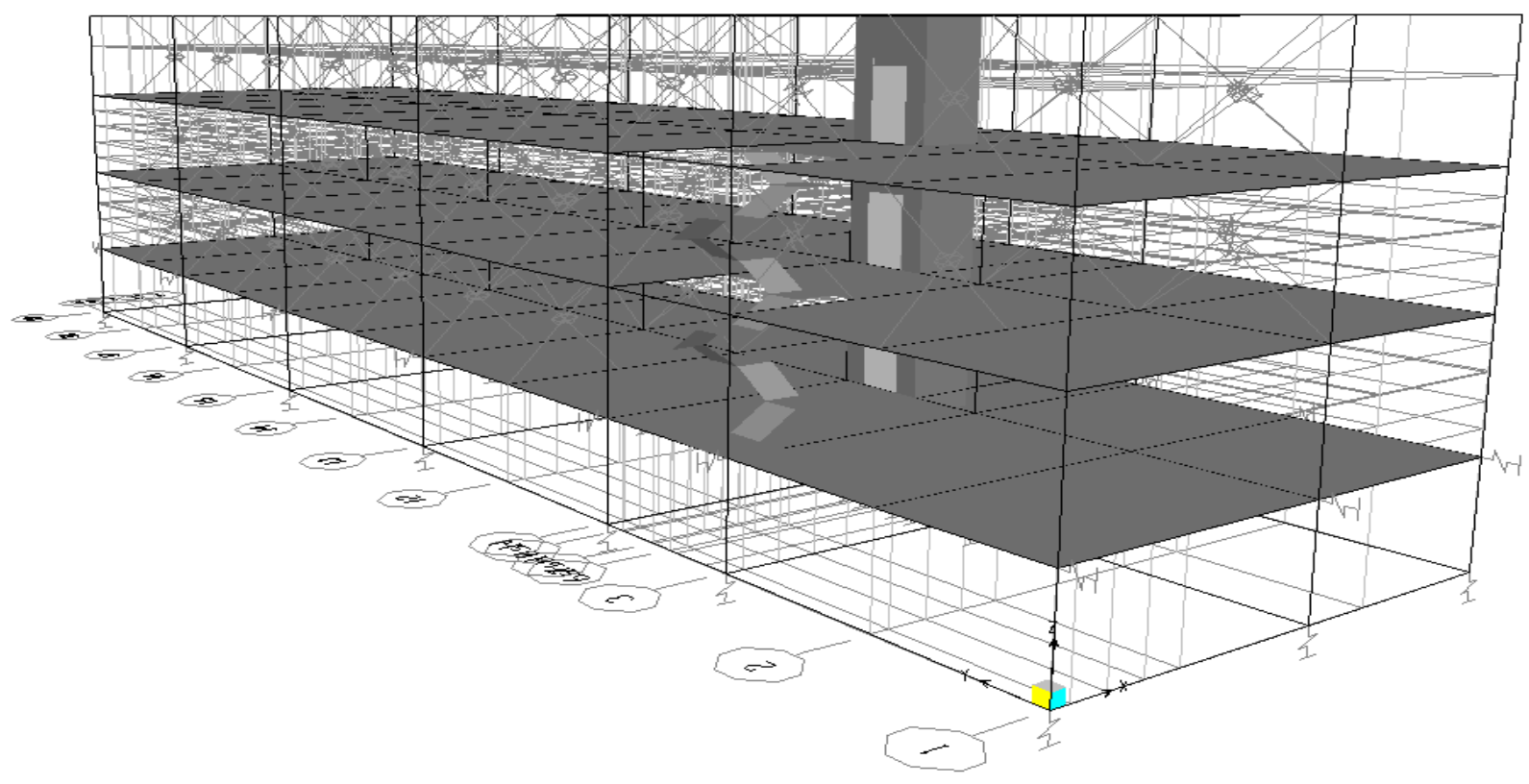

Figure 11. Three dimensional FEM showing beams, columns, floor slabs, shear core, partition walls, stairs and soil springs. Cladding has been removed from the view to show the inner details. 


\subsection{Results of FEM eigenvalue analysis and discussion}

The results of FEM eigenvalue analysis are presented in Table 2. The FEM results are compared with the largest recorded earthquake response of 18th November 2009, which had epicenter 10km south of Palmerston North. This earthquake has a Richter magnitude of 5.1 and PGA of $0.002 \mathrm{~g}$ as measured at the base of the building and PRA of $0.015 \mathrm{~g}$ at the roof.

Stage (a) of the FEM model consists of a bare frame model with fixed base. Stage (b) adds slabs to the bare frame increasing the stiffness and mass. Stage (c) includes shear core in the model which has increased the first, second and third mode frequencies by $2 \%, 11 \%$ and $13 \%$ respectively from the previous stage. At stage (d) the influence of NSCs is seen. The frequencies have changed significantly from the previous stage by $21 \%, 35 \%$ and $39 \%$ for the first, second and third mode, respectively. By modeling the soil in stage (e), the frequencies are reduced by $21 \%, 25 \%$ and $20 \%$, respectively, from the previous stage for the first, second and third modes, which shows a substantial influence of soil on the dynamic properties. The final stage (f) includes modeling of the partial submersion of building in which case the second and third mode frequencies are well in agreement with experimental values but the first frequency has still $18 \%$ difference compared to the experimentally determined value, although it has much improved from the previous stages. The building is shorter in X-direction and less stiff as compared to the Y-direction. One of the reasons of the frequency differences compared to the experimental values can be the assumed soil properties being different from the actual insitu properties. Also, the soil surrounding the building along the $\mathrm{X}$ and $\mathrm{Y}$ - direction can be different, as can be the soil underneath the foundations. It is therefore important to confirm the actual properties of soil and then use these for subsequent analyses. For this purpose an experiment using impact imparted by a sledgehammer and the spectral analysis of surface waves (SASW) method will be used to determine the in-situ characteristics of soil. This study can be considered as an initial investigation to see the influence of soil on dynamic characteristics. Soil properties therefore were assumed for this analysis for the time being. Model updating would be the next step after incorporating the in-situ soil characteristics in FEM to remove the differences between system identification and FEM results.

Table 2. Comparison of modal analysis results of various stages of FEM with identified frequencies during largest recorded earthquake response of 18 November 2009

\begin{tabular}{|llllllll|}
\hline \multicolumn{7}{c}{} & \multicolumn{7}{c|}{ Modal frequencies (Hz.) } \\
Modes & $\begin{array}{l}\text { (a) Bare } \\
\text { frame }\end{array}$ & (b) & (c) & $(\mathrm{d})$ & $(\mathrm{e})$ & $\begin{array}{l}\text { (f) Full details } \\
\text { with flexible base }\end{array}$ & $\begin{array}{l}\text { System } \\
\text { identification } \\
\text { results }\end{array}$ \\
\hline $1^{\text {st }}$ mode & 2.1 & 1.87 & 1.94 & 2.61 & 1.95 & 2.53 & 3.14 \\
X-trans & $(33 \%)$ & $(40 \%)$ & $(38 \%)$ & $(17 \%)$ & $(38 \%)$ & $(19 \%)$ & 3.47 \\
\hline $2^{\text {nd }}$ mode & 2.29 & 2.09 & 2.47 & 3.69 & 2.8 & 3.42 & 3.51 \\
Torsion & $(34 \%)$ & $(40 \%)$ & $(29 \%)$ & $(-6 \%)$ & $(19 \%)$ & $(1 \%)$ & 3.65 \\
\hline $3^{\text {rd }}$ mode & 2.31 & 1.94 & 2.38 & 3.76 & 3.06 & $(-4 \%)$ & $(-4 \%)$ \\
Y-trans & $(34 \%)$ & $(45 \%)$ & $(32 \%)$ & $(-7 \%)$ & $(13 \%)$ & \\
\hline
\end{tabular}

Note: The values in parenthesis show the percentage difference of the particular FEM stage results and system identification results.

\section{CONCLUSIONS AND FUTURE RESEARCH}

This study comprises two parts. First part involves system identification using a state-space subspace system identification technique to identify natural frequencies and damping ratios of a three storey RC concrete frame building with a shear core. This technique is considered as the most powerful technique for the natural input in the time domain. 
To evaluate the variation in the dynamic response, the relationships between the first three natural frequencies and corresponding damping ratios with PRA were developed for 50 recorded earthquakes. The main findings of this part of research are as follows:

(1) Due to unsymmetrical distribution of stiffness, all modes are coupled translational-torsional.

(2) PGA and PRA have a good correlation along both $\mathrm{X}$ and $\mathrm{Y}$ - directions.

(3) Modal frequencies are decreasing and damping ratios are increasing with the increase in the level of excitation except the case of nearly purely torsional mode where damping ratio shows no clear trend. The natural frequencies show a much clearer trend while damping ratios have more scattered values.

(4) State-space subspace system identification technique has the ability to identify very closely spaced modes.

(5) Since most of the earthquakes recorded so far are of low to medium intensity, it would be interesting to study the response of the buildings during stronger events when such data become available.

(6) In some events, it is observed that the first, second, third or any two of the modes are missing in the identification results. This finding suggests that dynamic response of the building is sensitive to the frequency content of the earthquakes.

The objective of the second part of the study was to highlight the importance of soil and NSCs modeling in the FEM of buildings. FEMs were developed in stages to see the influence of different elements of the structure. The following important conclusions are drawn from the study:

(1) NSCs significantly increase the frequencies by $22 \%, 35 \%$ and $38 \%$ for the first, second and third mode, respectively, while including soil properties in the model reduced the above modal frequencies by $21 \%, 26 \%$ and $19 \%$, respectively.

(2) Modeling the partial submersion in soil improved the agreement between experimental and FEM frequencies appreciably, except for the X-direction.

(3) To simulate the true soil behavior, actual in-situ soil characteristics will be incorporated in the FEM by testing the soil at site and using the SASW method.

(4) Model updating will be carried out to improve the agreement between FEM and measured dynamic characteristics.

\section{ACKNOWLEDGEMENT}

The authors would like to acknowledge GeoNet New Zealand staff for facilitating this research. Particular thanks go to Dr Jim Cousins, Dr S.R. Uma and Dr. Ken Gledhill.

\section{REFERENCES}

[1] Hart, G.C. and Yao, J.T.P., "System identification in structural dynamics," Journal of Engineering Mechanics ASCE 103, 1089-1104 (1976).

[2] Saito, T. and Yokota, H., "Evaluation of dynamic characteristics of high-rise buildings using system identification techniques," Journal of Wind Engineering and Industrial Aerodynamics 59(2-3), 299-307 (1996).

[3] Brownjohn, J.M.W. and Xia, P.Q., "Dynamic assessment of curved cable-stayed bridge by model updating," Journal of Structural Engineering ASCE 126(2), 252-260 (2000).

[4] Farrar, C.R., Sohn, H. and Doebling, S.W., "Structural health monitoring at Los Alamos National Laboratory," Proc. US-Korea Conference on Science and Technology, Entrepreneurship, and Leadership, Chicago, 2-5 September (2000). 
[5] Celebi, M., "Recorded earthquake responses from the integrated seismic monitoring network of the Atwood Building, Anchorage, Alaska," Earthquake Spectra 22(4), 847-864 (2006).

[6] Satake, N. and Yokota, H., "Evaluation of vibration properties of high-rise steel buildings using data of vibration tests and earthquake observations," Journal of Wind Engineering and Industrial Aerodynamics 59(23), 265-282 (1996).

[7] Trifunac, M.D., Ivanovic, S.S. and Todorovska, M.I., "Apparent periods of a building I: Fourier analysis," Journal of Structural Engineering ASCE 127(5), 517-526 (2001).

[8] Trifunac, M.D. and Todorovska, M.I., "Recording and interpreting earthquake response of full-scale structures," Proc. NATO Advanced Research Workshop on Strong-motion Instrumentation for Civil Engineering Structures, 131-155 (1999).

[9] Su, R.K.L., Chandler, A.M., Sheikh, M.N. and Lam, N.T.K., "Influence of non-structural components on lateral stiffness of tall buildings," Structural Design of Tall and Special Buildings 14(2), 143-164 (2005).

[10] Liew, Y.L., Duffield, C.F. and Gad, E.F., "The influence of plasterboard clad walls on the structural behavior of low rise residential buildings," Electronic Journal of Structural Engineering 2(2), 1-16 (2002).

[11] Van Overschee, P. and De Moor, B., "N4SID: Subspace algorithm for the identification of combined deterministic-stochastic systems," Automatica 30(1), 75-93 (1994).

[12] Van Overschee, P. and De Moor, B., Subspace identification for linear systems, Kluwer Academic Publishers, Dordrecht, the Netherlands (1996).

[13]Ewins, D.J., Modal Testing: Theory, Practice and Application, Research Studies Press Ltd, Baldock, Hertfordshire, UK (2000).

[14] Technical Committee BD-006-04-11, Structural design actions part 5 : Earthquake actions - New Zealand, Standards New Zealand (2004).

[15]Bowles, J.E., Foundation Analysis and Design, $5^{\text {th }}$ Edition, The McGraw-Hill Companies, Inc., New York (1996).

[16] Gazetas, G., "Formulas and charts for impedances of surface and embedded foundations," Journal of Geotechnical Engineering 117(9), 1363-1381 (1991).

[17] Whitman, R.V. and Richart, F.E., "Design procedures for dynamically loaded foundations," Journal of Soil Mechanics and Foundation Design ASCE 93(6), 169-193 (1967).

[18] Gaylord, M.W., Reinforced Plastics: Theory and Practice, $2^{\text {nd }}$ Edition, Cahners Publishing Co., New York (1974).

[19] Kanvinde, A.M. and Deierlein, G.G., "Analytical models for the seismic performance of gypsum drywall partitions,” Earthquake Spectra 22(2), 391-411 (2006). 